\title{
Examining Feasibility and Support in Prescribing a Plant-based Diet to Patients with Chronic Diseases in a Primary Care Practice
}

Michiel Adriaan van Zyl' ${ }^{1}$, Lesley Harris ${ }^{2^{*}}$ and Diane M Harper ${ }^{3}$

${ }^{1}$ School of Social Work, University of South Florida, USA

${ }^{2}$ Kent School of Social Work, University of Louisville, USA

${ }^{3}$ Community Outreach, Engagement and Health Disparities, University of Michigan Comprehensive Cancer Center, USA

*Corresponding author: Lesley Harris, Head of Gerontology Specialization, Kent School of Social Work, University of Louisville, USA, Tel: 502-852-8316; E-mail: lesley.harris@louisville.edu

Received October 20, 2018; Accepted November 13, 2018; Published November 19, 2018

\section{Retraction Note:}

The article entitled "Examining Feasibility and Support in Prescribing a Plant-based Diet to Patients with Chronic Diseases in a Primary Care Practice" has been accepted for publication in the Journal of Alternative and Integrative Medicine considering the statements provided in the article as personal opinion of the author which was found not having any conflict or biasness towards anything. As the article was a perspective one, information provided by the author was considered as an opinion to be expressed through publication.

Soon after the publication of the paper, we witnessed some serious concerns and many of them argued that the paper is a personal perspective and had not discussed any relevant ethical issue considered under the journal scope. Moreover, the paper is neither innovative nor thought provoking.

Publisher took decision to make the article online solely based on the reviewers suggestion which considered the article not but a personal opinion of the author. However, it is found that the article has some unavoidable mistakes and issues, therefore, being retracted from the journal. 